\title{
O SER E ESTAR DA AÇÃO DOCENTE: UMA REFLEXÃO NECESSÁRIA
}

"O rio atinge seus objetivos porque aprendeu a contornar seus obstáculos"

(Autor desconhecido)

\author{
Mikelli Cristina Pacito Benites ${ }^{1}$, Rosângela Regina Marcicano Capelasso ${ }^{1}$, Carmen Lúcia Dias ${ }^{2}$ \\ ${ }^{1}$ Mestranda do Programa de Pós-Graduação em Educação - UNOESTE/SP. ${ }^{2}$ Doutora em Educação e Docente do Programa de Pós- \\ Graduação em Educação - UNOESTE/SP
}

\section{RESUMO}

O presente estudo tem por objetivo apresentar reflexões de diferentes autores sobre o ser e estar dos professores frente à prática docente diante da função social e política que a profissão possui. Estas reflexões sobre as diversas mudanças e inovações na prática docente se fazem necessárias, pois contribuem para que desenvolva conhecimentos, habilidades, atitudes e valores que possibilitem superar os desafio de que o ensino como prática social Ihes coloca no cotidiano, constituindo uma identidade profissional. Refletir sobre a prática docente é tarefa significativa para a mudança da realidade escolar em que estamos inseridos.

Palavras-chave: Reflexão sobre a prática docente; ser e estar docente; função social da docência; prática docente.

\section{TO BE AND STAY AS A TEACHER: A NEEDED REFLECTION}

\begin{abstract}
The purpose of the present study is to present reflections of different authors about being and staying as a teacher in relation to the teaching practice facing the social and political function associated to the profession. These reflections about changes and innovations in the teaching-learning process aim to contribute to the education of critical citizens for the achievement of needed social transformations. To reflect about the teaching practice is a significant task for changing the school reality in which we are inserted.

Keywords: Reflection about the teaching practice; to be and stay as a teacher; social function of teaching; teaching practice.
\end{abstract}




\section{INTRODUÇÃO}

O presente artigo tem por finalidade apresentar pensamentos de diversos autores sobre a prática docente. Espera-se que este estudo venha contribuir para uma reflexão política e filosófica sobre o ser e estar dos professores e a constituição de sua identidade.

Nesse sentido, o foco deste estudo dirigese à reflexão sobre o exercício da função docente com ética e compromisso. Sabe-se que atualmente há uma grande preocupação com a democratização do ensino, haja vista que as propostas educacionais contemporâneas oferecem novas perspectivas na direção de transformar as escolas em instituições de acesso à maioria dos cidadãos e oferecer um ensino de qualidade.

Valendo-se da contribuição de Cordero (1986), Silva coloca que o presente tema enfoca a ação docente como dotada de uma função social; que o agir docente direcionará o caminhar de uma futura sociedade: "[...] o educador, individualmente considerado, tem de imprimir uma dimensão ética à sua atividade, a sua conduta tem de ser eticamente considerada".(1997, p. 163),

Diante das constantes mudanças sociais, entre vários fatores, no processo escolar o trabalho do professor se faz necessário "[..] enquanto mediação nos processos constitutivos da cidadania dos alunos, para o que concorre a superação do fracasso e das desigualdades escolares". (PIMENTA, 1996, p. 73).

As competências que um docente precisa adquirir para desempenhar sua "acção de ensinar" (ROLDÃO, 2007, p. 94), compreendem em conhecimento, habilidades, atitudes e pensamentos estratégicos. Para ensinar, não basta conhecer a matéria, é preciso, entre outras competências, transformar o saber disciplinar em conteúdos acessíveis aos alunos; um conjunto de recursos capaz de mobilizar e determinar ações pertinentes às diferentes situações que se reconstrói tanto na formação inicial quanto no transcurso do próprio exercício profissional.

\section{O SER E ESTAR DA AÇÃO DOCENTE}

A esse respeito, reflexões vem sendo realizadas (CUNHA, 1989; PERRENOUD, 1994; PIMENTA, 1994), resultando em teorias e pensamentos que buscam compreender melhor 0 processo de formação do professor e a constituição de sua identidade. Neste sentido, Pacheco (1995) assertivamente discorre que o professor deve ter a capacidade para resolver problemas e examinar com sentido crítico e sistemático a própria atividade que realiza.

A formação docente não se restringe ao curso de formação que lhes é oferecido nas Instituições de Ensino Superior, mas abrange conhecimentos práticos, vivências, dogmas e atitudes que podem ser de "caráter formal e não formal" (PACHECO, 1995, p.45).

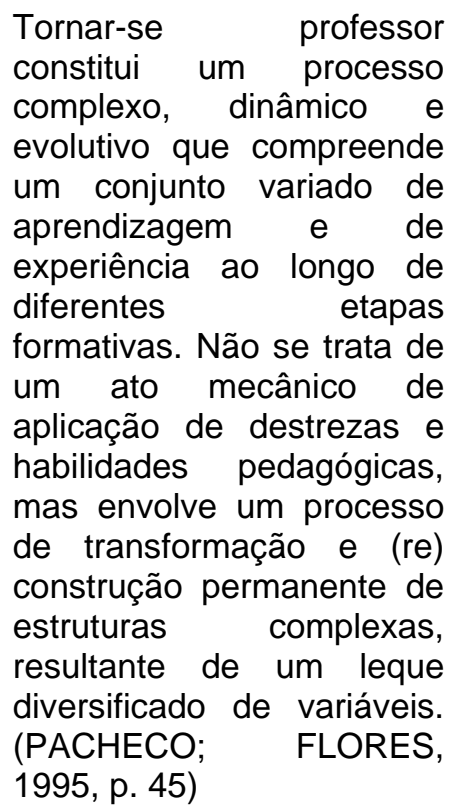

O processo de aprender a ensinar tratase de algo complexo e de natureza multifacetada (PACHECO; FLORES, 1995), que inclui o desenvolvimento de um conhecimento práticobase e de destrezas interpessoais, de mudanças na cognição bem como inclui aspectos de natureza afetiva, constituindo-se através de um 
contexto formativo (formação inicial) e de um contexto prático (período de prática de ensino e experiência de ensino posterior); o que pressupõe a análise do modo como se adquire e desenvolve o conhecimento profissional como também o estudo das influências pessoais e contextuais que o condicionam e/ou promovem.

Partindo desta reflexão espera-se que o futuro educador usufrua dos conhecimentos adquiridos por meio dos estudos teóricos e da prática, além daqueles oriundos de sua vivência, garantindo a capacidade de questionar sua atuação profissional, num processo contínuo rumo a estruturação de sua identidade.

A formação docente deverá proporcionar ao educador a capacidade de mobilizar os conhecimentos da teoria da educação e da didática necessários à compreensão do ensino como realidade social e ainda, investigar a própria atividade para, a partir dela, constituírem e transformarem os saberes-fazeres docentes, num processo contínuo de construção de suas identidades como professores.

Nesse contexto, surgem os questionamentos a respeito da prática de ensinar direcionando-se a refletir sobre a construção da identidade profissional do professor. Conforme Pimenta:

O que entendemos por construir a identidade? A identidade não é um dado imutável. Nem externo que possa ser adquirido. Mas é um processo de construção do sujeito historicamente situado. A profissão de professor, como as demais, emerge em dado contexto e momento histórico, como a resposta às necessidades que estão postas pela sociedade, adquirindo estatuto de legalidade.[...] (PIMENTA, 1996, p. 75).

Pimentel (1996) realiza várias reflexões sobre o processo de ensinar, questionando se ensinar é uma ciência, uma arte ou um conjunto de técnicas e ainda, o que define um excelente professor, o que o leva a se comprometer com o seu fazer e o que faz para ser considerado um professor bem-sucedido por seus pares.

A estes questionamentos não se produz resposta fácil e rápida, contudo, Pacheco esclarece que "[...] aprender a ensinar pressupõe a aquisição de determinados conhecimentos e destrezas, mas constitui também uma questão de individualidade e expressão pessoal [...]" (1999, p.45).

Para Pacheco (1999) o aprender a ensinar pressupõe a aprendizagem de estruturas muito complexas que, para serem compreendidas e explicadas, requerem a análise do processo de formação dos professores o qual envolve quatro componentes processuais: metacognição, a descontinuidade, a individualização e a socialização.

Sob esta perspectiva, aprender a ensinar é um processo que surge da articulação entre teoria e prática, mas fortemente dependente de um contexto prático, ou seja, todo conhecimento adquirido sobre os alunos, a escola, o contexto, os conteúdos e sobre si próprio, o docente não adquiriu pela teoria, mas sim por meio da reflexão da prática. Esta realidade Pacheco (1999) denomina de metacognição, onde o conhecimento do professor é resultante de uma relação entre a profissionalização e os saberes contextuais, deixando de lado o formalismo e atendendo, sobretudo à utilidade de seu saber frente ao seu desafio de ensinar.

Aprender a ensinar constitui-se como um processo evolutivo em que o ponto de partida é a sua experiência enquanto aluno e o ponto de chegada, a experiência enquanto professor, trajetória esta, marcada pela descontinuidade, ou seja, a transição de aluno a professor e o enfrentamento da crua e dura realidade da vida profissional do docente. 
Ainda, conforme Pacheco (1999), o processo de aprender a ensinar é individualizado, caracterizado por cada professor, pela suas crenças, atitudes, experiências prévias, motivações e expectativas. E, como quarto e último componente processual, aprender a ensinar é um processo de socialização, que ocorre em vários níveis e por diferentes influências que contribuíram para a formação da identidade profissional do professor.

Por estarmos refletindo sobre o ser e estar da função docente faz-se necessário a contribuição de Lacey:

Tornar-se professor é
tornar-se criativamente
envolvido em tarefas e
situações comuns apenas
aos professores. Também
envolve preocupar-se com
constrangimentos a que os
outros não se submetem.
Estas experiências
partilhadas e problemas
comuns dão origem a um
conjunto comum de
interesses, a determinadas
maneiras de ver o mundo,
de o interpretar e de obter
uma visão do mundo,
resumindo, do uma
perspectiva de professor.
(LACEY apud PACHECO,
1999, p.49).

O autor, ainda direciona seu pensamento durante o texto no sentido de que aprender a ensinar, nesta perspectiva, envolve aprender a textura da aula e o conjunto de comportamentos congruentes com as solicitações sociais desses lugares.

Tais questionamentos e reflexões são tão presentes para Pacheco (1999), que pode-se verificar que este reflete sobre a formação do professor e resume que o mais importante para o surgimento do profissional docente eficaz e amplo, consiste em desenvolver a sua capacidade para solucionar problemas, e ainda, que seja capaz de avaliar criticamente seu papel na função que realiza, adquirindo competência para tomar as decisões corretamente.

Outros autores como Roldão (2007) caracterizam e distinguem a "acção de ensinar" como:

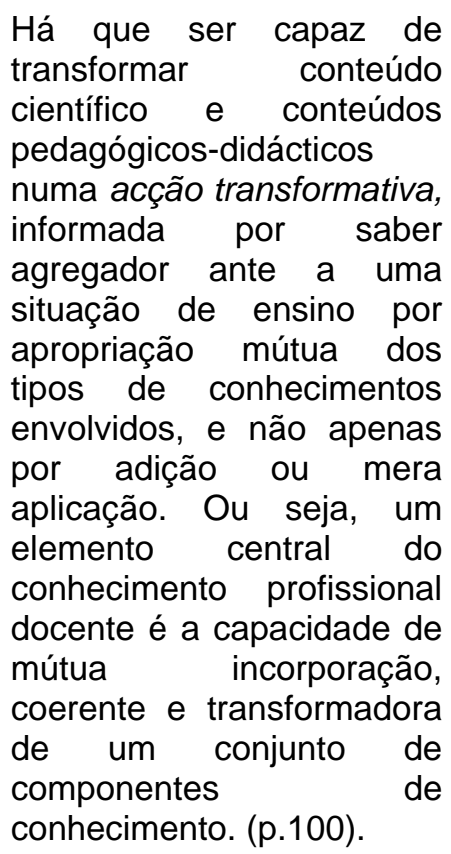

Ainda conforme ressalta a autora, o docente deve realizar "questionamento permanente" de sua prática, do conhecimento previamente adquirido e das experiências anteriores, ante a imprevisibilidade que o docente se depara em sua função. A autora nomeia a prática como "acção de ensinar", fundada num saber seguro que surge dos saberes formais e experienciais questionados e refletidos. Assim, para Roldão:

Torna-se saber profissional docente quando e se o professor o recria mediante um processo mobilizador e transformativo em cada acto pedagógico, contextual, prático e singular. Nessa singularidade de cada situação o profissional tem de saber mobilizar todo o tipo de saber prévio que possui, transformando-o em fundamento do agir informado, que é o acto de ensinar enquanto construção de um processo de aprendizagem de outros 
e por outros - e, nesse sentido, arte e técnica, mas fundada em ciência. (2007, p.101).

A função de ensinar é socioprática e por isso, deve ser discutida a própria ação e a dos outros, buscando um domínio sobre o saber. Dominar este saber é para a autora algo específico que distancia dos conteúdos, mas caminha para e em direção ao saber ensinar.

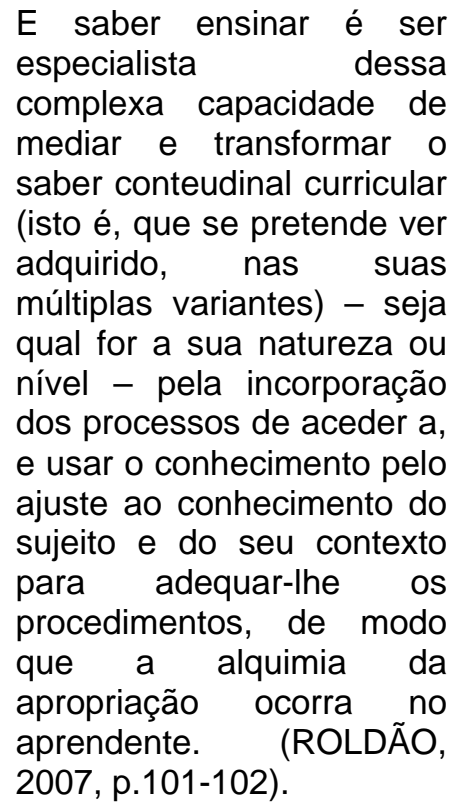

Saber produzir essa mediação, para a autora, não é um dom, nem uma técnica nem mesmo uma vocação: [...] "É ser um profissional de ensino, legitimado por um conhecimento específico, exigente e complexo [...]" (ROLDÃO, 2007, p.102).

A formação e a constituição de um docente é um processo complexo, singular e detalhado, e questionamentos sobre o tema surgem com grande ênfase entre os educadores e ainda, entre os formadores de professor. Parece ocorrer um certo descontentamento com a formação dos professores e suas práticas em sala de aula.

Neste sentido, para Pimentel, o processo de aprendizagem e formação do professor ocorre concomitantemente durante o tempo em que também ensina. Assim declara: “[...] a formação do professor se dá enquanto ensina. Não posso deixar de afirmar que me eduquei educando".(1996, p. 16).

Silva (1997), ressalta que a formação dos docentes também se deu durante um período histórico/social/político e repleto de características próprias que influenciaram a construção do seu ser e estar docente e que será disseminada em sua prática em sala de aula. Exercer a função docente diante de uma dimensão socializadora e consciente da formação dos futuros cidadãos, somente tornar-se-á possível a partir das reflexões e questionamentos que o educador realizará sobre suas filosofias, ideologias e práticas.

Para que isso aconteça, é necessária a efetivação das ações docentes relacionadas com a necessidade de mudanças de seus modos habituais de agir e, ao mesmo tempo, de desejar essa mudança. Torna-se claro que a função docente e a formação do aluno estão indissociáveis, e as mudanças da realidade sociais são conseqüências desta interação.

As modificações acontecerão à medida que o professor atribuir à sua formação a necessidade de que isso ocorra,

[...] buscando compreender
o conceito de necessidade
como mudança ou direção
desejada, para
fundamentar a tese de que
novos saberes fossem
incorporados ao habitus
dos professores, novos
espaços de transformação
poderiam ser criados no
contexto da escola e da
sala de aula - revelando
uma maneira de ser e estar
na profissão. (ABDALA
2006, p.16, grifo do autor).

A autora ressalta que a construção da identidade do professor se dá pela necessidade e perspectivas que assumem em relação à sua formação e desenvolvimento profissional e pela 
importância que colocam na escola enquanto contexto de produção docente.

\subsection{Práticas e saberes docentes}

Pimentel (1996) destaca em sua pesquisa realizada em uma Universidade Pública, com docentes de diferentes áreas - Exatas, Tecnológicas, Biológicas, Humanas e Artes - dois grupos de professores que se posicionavam em extremidades opostas: de um lado, os que acreditavam ser 0 ensino-aprendizagem um processo em construção e no outro, os que consideravam o ensino como um processo de transmissão.

A autora também apresenta o pensamento de um grupo de professores que chama de "representativos" - os que reagem à desumanização como um desafio, buscando novas perspectivas para o desenvolvimento humano:

Estes professores estão
dizendo que mudar espaço
de ensino não significa
apenas mudar a
metodologia ou adotar os
procedimentos de um
professor bem-
sucedido...Significa
questionar profundamente
as próprias posições
filosóficas, epistemológica,
políticas e ideológicas.
Significa entender-se como
ser histórico e perguntar-se
sobre suas
intencionalidades, o que é
diferente de simplesmente
discutir, informar,
polemizar. (PIMENTEL,
1996, p. 37).

Neste sentido, concretizam sua responsabilidade, assumindo e se comprometendo com o outro - o seu aluno - num processo de aprofundamento de consciência, praticando, entre outras, as chamadas virtudes da verdade.

Esta reflexão é muito forte e significativa, pois muitas vezes em reuniões de Trabalho
Pedagógico, nos deparamos com companheiros de trabalho que justificam a falta de mudança no contexto escolar baseando-se em infinitas justificativas, sem questionar seus fundamentos e pensamentos filosóficos e sem refletir sobre sua própria prática.

Sobre o processo de formação do professor, Tardiff (2002, p.11) coloca que o saber não é uma coisa que flutua no espaço:

[...] o saber dos professores é o saber deles e está relacionado com a pessoa e a identidade deles, com a sua experiência de vida e com sua história profissional, com suas relações com os alunos em sala de aula e com os outros atores escolares na escola, etc.

Valorizar o saber docente é fundamental para alcançar um processo ensino-aprendizagem de qualidade, pois as práticas dos professores estão intimamente relacionadas com suas experiências em sala de aula.

No Brasil, nas últimas décadas vivenciamos 0 desprezo às práticas docentes construídas durante anos de profissão frente às novas propostas educacionais. Este artigo não tem por finalidade discorrer sobre os conflitos que surgiram com as propostas educacionais dos últimos tempos, contudo, problemas e a queda na qualidade de ensino são notáveis em nosso país. Não queremos aqui justificar que tal perda na educação foi provocada unicamente pela desvalorização da pratica docente, mas parecenos que esta se soma aos demais fatores.

Ainda para o autor,

[...] o saber dos professores não é um conjunto cognitivo definido de uma vez por todas, mas um processo em construção ao longo de uma carreira profissional na qual aprende progressivamente a dominar seu ambiente de trabalho, ao mesmo tempo 
em que se insere nele e o interioriza por meio de regras de ação que se tornam parte integrante de sua 'consciência prática'. (TARDIFF, 2002, p. 14).

Diante de tal realidade, nota-se que a docência tem uma dimensão socializadora, pois o professor, ao contribuir para a formação dos alunos, dirige-se por intermédio deles à configuração da própria sociedade. Silva (1997) inclui também, uma dimensão política à função docente, pois esta formará cidadãos plenos, capazes de analisar, refletir, criticar e apresentar propostas direcionadas para modificar a realidade em que está inserido.

Considerando que as mudanças sociais ocorrem entre vários fatores, no processo escolar, o professor se apresenta como o mediador do processo de formação deste aluno em cidadão transformador da sociedade.

\section{O BOM PROFESSOR}

Em apresentação realizada no III Congresso Estadual Paulista sobre a Formação de Educadores em Águas de São Pedro - SP, em maio de 1994, a pesquisadora Gebran (1996) levantou em sua pesquisa intitulada " $A$ identidade de um bom professor: o ser e fazer", elementos que pudessem identificar um bom professor. Coletou dados que caracterizaram o "ser e o estar" de uma profissional docente de uma escola pública, que era considerada pelos demais professores, alunos e pais, como uma boa professora.

Torna-se evidente no texto apresentado, que o comprometimento daquela professora, sua postura de trabalho, o respeito pelo educando e pelo seu próprio trabalho, sua criatividade e dedicação e sua própria identidade conduziam aquela educadora ao reconhecimento. Contudo, a autora relata que a professora "não se deixava levar pelos dogmas tradicionais e conservadores estabelecidos em sua formação, mas reagia, buscando redimensionar a sua visão de mundo, de sociedade e de educação".

Neste sentido, a pesquisadora ressalta que este processo não é tão tranqüilo, já que o redimensionar suas filosofias e pensamentos poderá conduzir a certa segurança ou insegurança, que se vinculam a sua formação e à trajetória profissional.

Assim, durante seu texto, deixa claro que os objetivos daquela professora estavam determinados, comprometendo-se com o seu ser e estar na ação docente, ou seja, uma preocupação constante com a formação integral do aluno. (grifo nosso).

A análise realizada por Gebran (1996) sobre a prática docente daquela professora envolveu questões significativas que demonstraram o comprometimento daquela profissional, com suas ações planejadas, os objetivos estabelecidos, o conhecimento, as atividades propostas e desenvolvidas, a avaliação, a relação com a instituição e a relação com os alunos.

Conclui seu texto, ressaltando que 0 processo da construção do conhecimento entre aquela docente e seus alunos se desenvolvia de maneira muito solta, agradável e harmoniosa, e sua identidade refletia em seu ser e fazer docente, tratando-se de uma profissional comprometida e competente.

É importante salientar que muitos questionamentos quanto à formação dos docentes, seu comprometimento com sua formação e seu agir durante o processo de aprendizagem do educando, mas, o que se ressalta é que não há que se analisar determinada ação docente sem conhecer antes em que contexto aquele educador foi formado, aspectos históricos de sua vida, suas filosofias e dogmas; enfim, o seu agir como professor está 
intimamente relacionado com a sua identidade e ainda mais, com o grupo em que está inserido.

Pimenta (2006), em sua obra "Professor Reflexivo no Brasil" teve por objetivo explicitar e discutir as origens, os pressupostos, os fundamentos e as características do conceito professor reflexivo, buscando realizar uma análise crítica deste conceito diante do movimento de valorização da formação e da profissionalização dos professores que surgiu em diferentes países a partir de 1990. A autora comenta o pensamento de Schon que propõe uma formação profissional baseada numa epistemologia da prática, ou seja, na valorização da prática profissional como um momento de construção de conhecimento, de reflexão, análise e problematização sobre o trabalho realizado.

Esse conhecimento na ação, citado por Pimenta em referência ao pensamento de Schon, é o conhecimento implícito, interiorizado, que está na prática e que, portanto, não a precede, sendo construído pelos profissionais no seu dia-a-dia, configurando um hábito.

No entanto, esse conhecimento não é suficiente frente à situações novas que extrapolam a rotina, os profissionais criam, constroem novas soluções, novos caminhos, 0 que se dá por um processo de reflexão na ação. A partir daí, constroem um repertório e experiências configurando-se como um conhecimento prático.

Contudo, este repertório diante de novas situações, poderá não superá-las, surgindo a necessidade de uma nova busca, análise, contextualização, possíveis explicações, uma compreensão de suas origens, problematização e um diálogo com outras perspectivas, também, uma apropriação de teorias sobre o problema, uma investigação, ou seja, uma reflexão sobre a reflexão na ação.

A análise empreendida no presente artigo coloca em evidência a indiscutível contribuição da reflexão no exercício da docência para a valorização da profissão docente, dos saberes dos professores, do trabalho coletivo destes e das escolas enquanto espaço de formação contínua. Isto porque, assinala que o professor pode produzir conhecimento a partir da prática, desde que reflita intencionalmente sobre ela, problematizando os resultados obtidos com 0 suporte da teoria. E, portanto, como pesquisador de sua própria prática, atuando em diferentes situações e resolvendo conflitos; bem como professores/pesquisadores, capazes de participarem ativamente das reformas curriculares e escolares, deixando de ser meros executores das decisões tomadas em outras instâncias.

\section{CONSIDERAÇÕES FINAIS}

Como visto na Introdução deste trabalho, sabemos que atualmente há uma grande preocupação com a democratização do ensino, haja vista que as propostas educacionais contemporâneas oferecem novas perspectivas na direção de transformar as escolas em instituições de acesso à maioria dos cidadãos e oferecer um ensino de qualidade. Isso nos leva a refletir ao exercício da função docente com ética e compromisso, bem como uma reflexão política e filosófica sobre o ser e estar dos professores e a constituição de sua identidade.

Diante dos pensamentos de diversos autores sobre a prática docente, esperamos que este estudo tenha contribuído para uma reflexão do ser e estar dos professores e a constituição de sua identidade.

As reflexões sobre a formação do professor e a construção do ser e estar, não significa centrar-se somente nas mudanças de propostas educacionais, nem mesmo nas teorias que fundamentam as práticas. Abrange a formação do docente, que é singular particularizada, complexa e contextualizada historicamente, ligada por sua vez, à sua 
identidade, filosofias, posicionamentos políticos e epistemológicos que foram se estabelecendo durante sua formação.

Acreditamos que o sentir-se na função docente é assumir um compromisso social, ético e político frente à formação dos cidadãos que constituirão a sociedade vindoura.

Concluindo, ressalta-se que o sucesso do professor enquanto mediador do conhecimento não está centrado somente nos estudos teóricos realizados durante a sua formação, contudo, abrange elementos de grande complexidade como sua vivência, seus estudos, sua identidade, técnicas, saberes próprios, filosofias, dogmas e, acima de tudo, somente alcançará mudanças rumo às novas conquistas, se sentir necessário.

\section{REFERÊNCIAS}

ABDALA, M. F. B. O senso prático de ser e estar na profissão. São Paulo: Cortez, 2006. (Coleção Questões da Nossa Época. v.128).

GEBRAN, R. A. A identidade do bom professor: o ser e o fazer. Didática, São Paulo, v.31, 1996, p. 29-45

PACHECO, J. A. O pensamento e a ação do professor. Porto. Porto Editora, 1995.

PACHECO, J. A. e FLORES, M. A., Formação e avaliação de professores. Porto Editora LDA. Portugal, 1999.

PIMENTA, S.G. Formação de Professores saberes da docência e identidade do professor. R. Fac. Educ., São Paulo, v. 22, n.2, p. 72-89, jul/dez 1996.

PIMENTA, S. G. Professor reflexivo: construindo uma crítica. In: Pimenta, S.G. Ghedin, E. (Org.). Professor reflexivo no Brasil. 4. ed. São Paulo: Cortez, 2006.

PIMENTEL, M. da G. O professor em construção. 9 ed. Campinas: Papirus, 1996.

ROLDÃO, M. do C. Função docente: Natureza e construção do conhecimento profissional. Revista Brasileira de Educação $\mathrm{Vol}$ 12, n. 34, jan/abr.2007.
SILVA, M. de L. A docência é uma opção ética. In: ESTRELA, M. T. (Org.). Viver e construir a profissão docente. Portugal: Porto Editora, 1997. p.161-190.

TARDIFF, M. Saberes docentes e formação profissional. Rio de Janeiro, Petrópolis: Vozes, 2002. 